\title{
Use of sodium bicarbonate as an inexpensive general anesthetic for juvenile red tilapia hybrids
}

\author{
Arlene L. Avillanosa $\cdot$ Christopher Marlowe A. Caipang
}

Received: 23 March 2019/ Accepted: 5 August 2019/Published online: 16 August 2019

(C) The Author(s) 2019

\begin{abstract}
In the context of responsible handling and good welfare practices, fish must be anesthetized to lessen the effects of the stressors to the fish. There are a number of commercially available anesthetics that are being marketed, but some of these products are not easily accessed by fish farmers in some aquaculture sites particularly those in the rural areas or these chemicals are expensive for the small-scale fish farmers to purchase. The use of sodium bicarbonate, commonly known as baking soda, was tested as an alternative and inexpensive anesthetic during fish handling and transport using red tilapia hybrids as a model fish species. Red tilapia hybrid juveniles with weights ranging 1-4.5 $\mathrm{g}$ were exposed to two concentrations of sodium bicarbonate at 50 and $100 \mathrm{~g} \mathrm{l}^{-1}$ in both fresh- and brackishwater (20 ppt) conditions. Regardless of the dose of the anesthetic, juvenile red tilapias that were reared in brackishwater took a longer time to be fully anesthetized than those reared in freshwater. In both rearing environments, the concentration of the anesthetic has an effect on the time to induce anesthesia of the fish. In addition, the time to full recovery of the fish was not significantly different in both rearing environments and was not affected by the dose of the anesthetic. A concentration of at least $50 \mathrm{~g}^{-1}$ is recommended for anaesthetizing red tilapia hybrid juveniles in both rearing environments at water temperatures in the range of $26-29{ }^{\circ} \mathrm{C}$.
\end{abstract}

Keywords Anesthesia $\cdot$ Aquaculture $\cdot$ Handling $\cdot$ Nursery $\cdot$ Sedation $\cdot$ Welfare

\section{Introduction}

The necessity of transporting and handling live fish during aquaculture operations has led to the development of techniques to anaesthetize fish without impairing their health or commercial value. Unanesthetized fish suffer tremendous amount of stress during catching, transporting or when submitted to manipulation and disturbance of its natural environment. The stress and pain have crucial effects on the physiological responses and biochemical profile, inducing endocrine and metabolic disturbance in the fish (Iwama et al. 1989; Bruecker and Graham 1993; Yoshikawa et al. 1994; Bastos-Ramos et al. 1998). Recent research studies have

A. L. Avillanosa $(\bowtie) \cdot$ C. M. A. Caipang

College of Fisheries and Aquatic Sciences, Western Philippines University, Puerto Princesa Campus,

Puerto Princesa 5300, Palawan, Philippines

e-mail: arlavillanosa@yahoo.com

Present Address:

C. M. A. Caipang

College of Liberal Arts, Sciences, and Education and the Center for Chemical Biology and Biotechnology, University of San Agustin, General Luna St., Iloilo City 5000, Philippines 
suggested that fish are capable of pain perception (Sneddon 2012). These investigations have demonstrated that fish possess receptors that can detect potentially painful stimuli, which are very similar to those found in mammals (Sneddon et al. 2003; Ashley et al. 2007).

Although a wide variety of chemical anaesthetics are available (Bell 1987; Iwama and Ackerman 1994), the economic, safety and regulatory considerations have rendered the use of chemical anaesthetics on food fish inappropriate (Iwama and Ackerman 1994; Prince et al. 1995; Bernier and Randall 1998). An efficient, predictable, and safe method for anesthesia of fish is needed because an increasing number of valuable species are being cultured, transported and subjected to various handling procedures.

One of the safer chemical anesthetics that can be used in anesthetizing fish is sodium bicarbonate. It is also known as baking soda and when dissolved in water, it liberates carbon dioxide, which has an anesthetic effect on fish (Bowser 2001). This gas was initially described as a fish anesthetic by Fish (1943) and is proven to be safe for humans; thus, there are no restrictions in its use (Summerfelt and Smith 1990). When used as an anesthetic, carbon dioxide gas is bubbled in the water directly through an airstone that is connected to a source or indirectly by the addition of sodium bicarbonate as a source of carbon dioxide (Altun et al. 2009).

There are a number of studies that have been conducted to test the efficiency of sodium bicarbonate as an anesthetic in both salmonids (Booke et al. 1978; Keene et al. 1998) and non-salmonids (Booke et al. 1978; Altun et al. 2009). In an earlier study involving Nile tilapia, Oreochromis niloticus, demonstrated the effectiveness of using this chemical anesthetic, which is affected by the dose and the size of the fish (Opiyo et al. 2013). In spite of these information from previous studies, there is limited data that show the efficiency of this chemical anesthetic on the same species of fish at different rearing salinities. Because both brackishand seawater contain a significant amount of carbonates, these might have an impact on the action of sodium bicarbonate when added to these media. As aquaculture can be carried out in fresh-, brackish- and seawater conditions, the potency of sodium bicarbonate as a fish anesthetic in these conditions must be assessed. Hence, using red tilapia hybrid juveniles, a euryhaline fish as a model species, the effectiveness of using sodium bicarbonate as a chemical anesthetic was determined in both fresh- and brackishwater conditions.

\section{Materials and methods}

Experimental design

The study was conducted at the Aquatic Science Laboratory (ASL), College of Fisheries and Aquatic Sciences (CFAS), Western Philippines University (WPU)—Puerto Princesa Campus, Palawan, Philippines. Red tilapia hybrid juveniles with weights ranging 1-4.5 g were collected from freshwater and brackishwater (20 ppt) circular tanks and acclimatized to their respective environments for 1 week prior to the experiment. During acclimation, the fish were fed twice daily with commercial fish feed pellets at $5 \%$ body weight. Twenty-five (25) freshwater red tilapia juveniles and the same number of juvenile fish from the brackishwater tanks were placed in 100-L glass aquaria a day before the experiment and were starved to optimize the experimental conditions during the exposure of the fish to the anesthetic. This number of fish was reared to provide an allowance for unexpected mortality before the experiment. All procedures were supervised by an accredited expert in laboratory animal science and carried out according to the guidelines on the protection of animals used for research purposes.

Commercially available baking soda was purchased and was used as the source of the sodium bicarbonate. In a previous study, Opiyo et al. (2013) found that at a concentration of $50 \mathrm{~g}^{-1}$, tilapia juveniles were able to reach full anesthesia within 2 min and did not result in mortality. Hence, this study tested two concentrations of the sodium bicarbonate: 50 and $100 \mathrm{~g}^{-1}$ in inducing full anesthesia in red tilapia hybrid juveniles without causing any mortality post-recovery.

Induction to anesthesia and recovery

On the day of the experiment, nine (9) 1-L glass aquaria were filled with either fresh- or brackishwater (20 ppt) and added with either 50 or $100 \mathrm{~g} \mathrm{l}^{-1}$ of baking soda. This set of aquaria was designated as anesthesia aquaria. The water was stirred continuously until complete dissolution. The experiment was done within 30 min after 
complete dissolution of the baking soda. Another set of nine 1-L glass aquaria for each water type was used as a recovery aquarium for the fish. Two experimental runs were done (one for freshwater and another fro brackishwater) and a total of eighteen (18) tilapia juveniles were used for each experiment.

For the experiments in freshwater and brackishwater conditions, one fish was placed in each anesthesia aquarium and observed until the fish reached Stage III anesthesia following the description of Iwama et al. (1989) and Palić et al. (2006). The fish at Stage III anesthesia were characterized to have total loss of equilibrium and gross loss of body and opercular movements (Table 1). Once Stage III anesthesia was reached, the fish was immediately scooped out from the anesthesia aquarium and immediately transferred to the recovery aquarium and observed until the fish attained Stage III recovery, which was characterized by attainment of full equilibrium with pre-anesthetic appearance (Table 1). All fish of almost uniform sizes from both the fresh- and brackishwater environments were randomly taken and exposed to either of the two doses of the anesthetic. Analysis of the weights of the fish among the groups showed no significant differences (data not shown) in the average weights indicating homogeneity of the fish samples that were used in the experiment.

The time of induction to full anesthesia and the time to complete recovery for each fish were recorded by three trained personnel to ensure accuracy and reliability of the collected data. Water $\mathrm{pH}$ was taken before and after addition sodium bicarbonate to determine if there were changes in the acidity or basicity of the water. All anesthetized fish were held for an additional 5 days post-exposure to monitor their behaviour and possible mortality.

Data analyses

Means and standard deviations for time to anesthesia and recovery of the red tilapia hybrid juveniles were obtained at two concentrations of the anesthetic at both fresh- and brackishwater conditions. The data in the two groups were compared using Student's $t$ test for independent samples. All statistical computations were performed at the 0.05 probability level. Analyses were performed using the statistical package of Microsoft Excel 2010.

\section{Results}

The time taken for induction of anesthesia and recovery of juvenile red tilapia hybrids in freshwater following immersion in water containing two concentrations of sodium bicarbonate is shown in Fig. 1. Induction of Stage III anesthesia of juvenile red tilapia hybrids when immersed in freshwater containing $50 \mathrm{~g} \mathrm{l}^{-1}$ sodium bicarbonate ranged 118-214 s (median: $185 \mathrm{~s}$ ), while at a concentration of $100 \mathrm{~g}^{-1}$, the induction of anesthesia ranged 26-99 s (median: $83 \mathrm{~s}$ ). Although both concentrations of the anesthetic resulted in full induction of anesthesia in juvenile fish at an average of less than $3 \mathrm{~min}$, the fish were induced to full anesthesia faster when immersed at a higher concentration of the anesthetic $(p<0.05)$. The recovery time of the juvenile fish following immersion in freshwater with $50 \mathrm{~g} \mathrm{l}^{-1}$ sodium bicarbonate ranged 51-275 s (median: $83 \mathrm{~s}$ ), while at $100 \mathrm{~g} \mathrm{l}^{-1}$, the recovery time ranged 62-122 s (median: $74 \mathrm{~s}$ ). At both concentrations of the

Table 1 Stages of anesthesia and recovery in fish

Description

\begin{tabular}{ll}
\hline & Description \\
\hline Stages of anesthesia & \\
I & Fish exhibits loss of equilibrium \\
II & Loss of body movements; slow opercular movement \\
III & Opercular movement ceases; loss of body movement \\
Stages of recovery & \\
I & No body movement; start of opercular movement \\
II & Normal opercular movement; body movement starts to normalize \\
III & Full equilibrium regained with pre-anesthetic appearance \\
\hline
\end{tabular}

These stages of anesthesia and recovery were adapted from Iwama et al. (1989) 

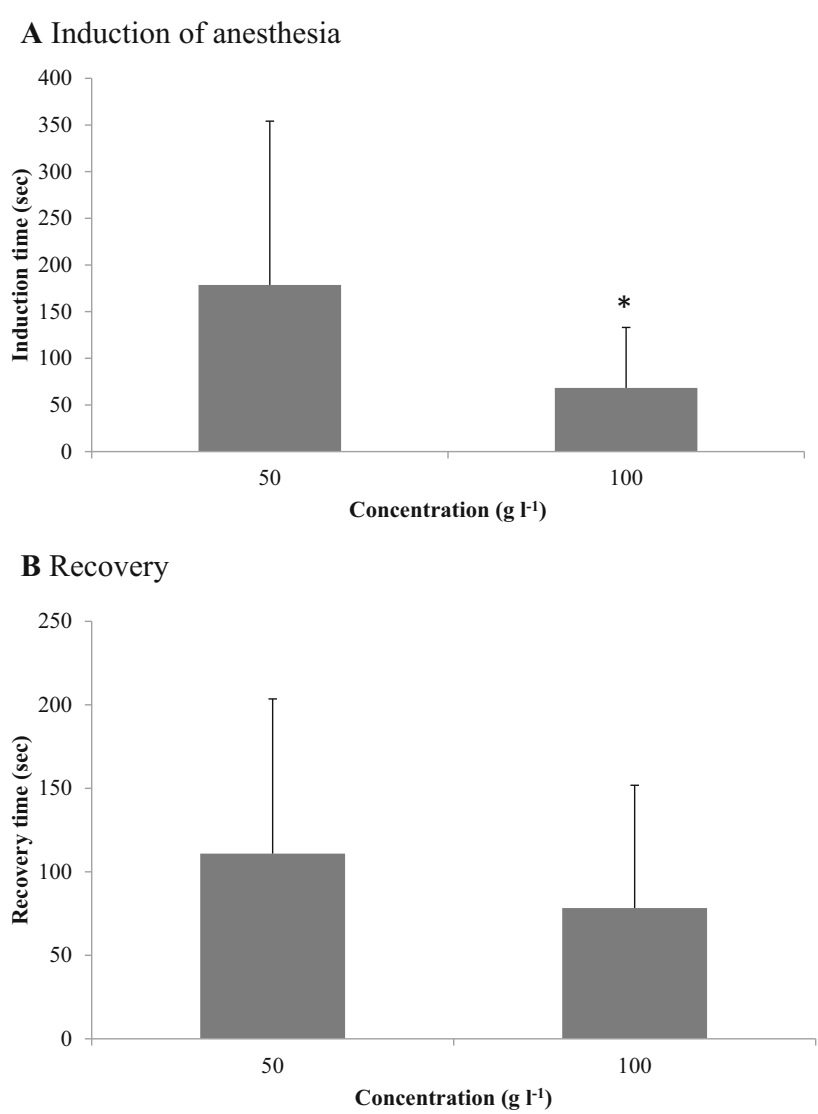

Fig. 1 Induction of anesthesia and recovery of red tilapia hybrid juveniles during immersion in freshwater containing 50 and $100 \mathrm{~g} \mathrm{l}^{-1}$ sodium bicarbonate. Column bars with asterisk indicates significant difference at $p<0.05 . N=9$

anesthetic, the fish were able to recover at an average of less than 2 min, although no significant differences $(p>0.05)$ in the recovery time of the fish were observed in both doses of the anesthetic.

Figure 2 shows the induction of anesthesia and recovery of red tilapia hybrid juveniles following immersion in brackishwater containing sodium bicarbonate. The fish attained Stage III anesthesia in the range of 102-305 s following immersion in water that contained a concentration of $50 \mathrm{~g}^{-1}$ of baking soda, while they were fully anesthetized in 75-189 s when a concentration of $100 \mathrm{~g} \mathrm{l}^{-1}$ sodium bicarbonate was used. The induction of anesthesia in fish in brackishwater was faster $(p<0.05)$ when a higher concentration of sodium bicarbonate was used. Recovery of the fish was in the range of 58-133 s and 55-223 s following immersion in water containing 50 and $100 \mathrm{~g} \mathrm{l}^{-1}$, respectively. Moreover, no significant differences $(p>0.05)$ in the time for recovery of fish were observed following immersion at both concentrations of the anesthetic.

The relationships of the effects of both the dose of anesthetics and rearing environment on the induction of anesthesia and recovery are shown in Tables 2 and 3. In terms of the time required for the induction of anesthesia and recovery, red tilapia juveniles had a significantly higher $(p<0.05)$ induction time to be fully anesthetized than the time that is required for them to recover when a dose of $50 \mathrm{~g} \mathrm{l}^{-1}$ sodium bicarbonate was used in both fresh- and brackishwater (Table 2). However, when a dose of $100 \mathrm{~g} \mathrm{l}^{-1}$ was used in both salinity levels, no significant differences $(p>0.05)$ were observed between the time to induce anesthesia and recovery.

In terms of the salinity levels of the water, induction to anesthesia in fish was significantly longer $(p<0.05)$ in brackish- than in freshwater at both doses of the anesthetic. However, the time to attain full recovery was not significantly different $(p>0.05)$ in both salinity levels and the dose of the anesthetic used.

The induction of anesthesia in fish when immersed in two concentrations of sodium bicarbonate progressed in stages. Regardless of the dose and salinity, the fish exhibited rapid swimming behaviour upon immersion in the water with anesthetic. This was followed by erratic swimming behaviour, gradual loss of equilibrium and 

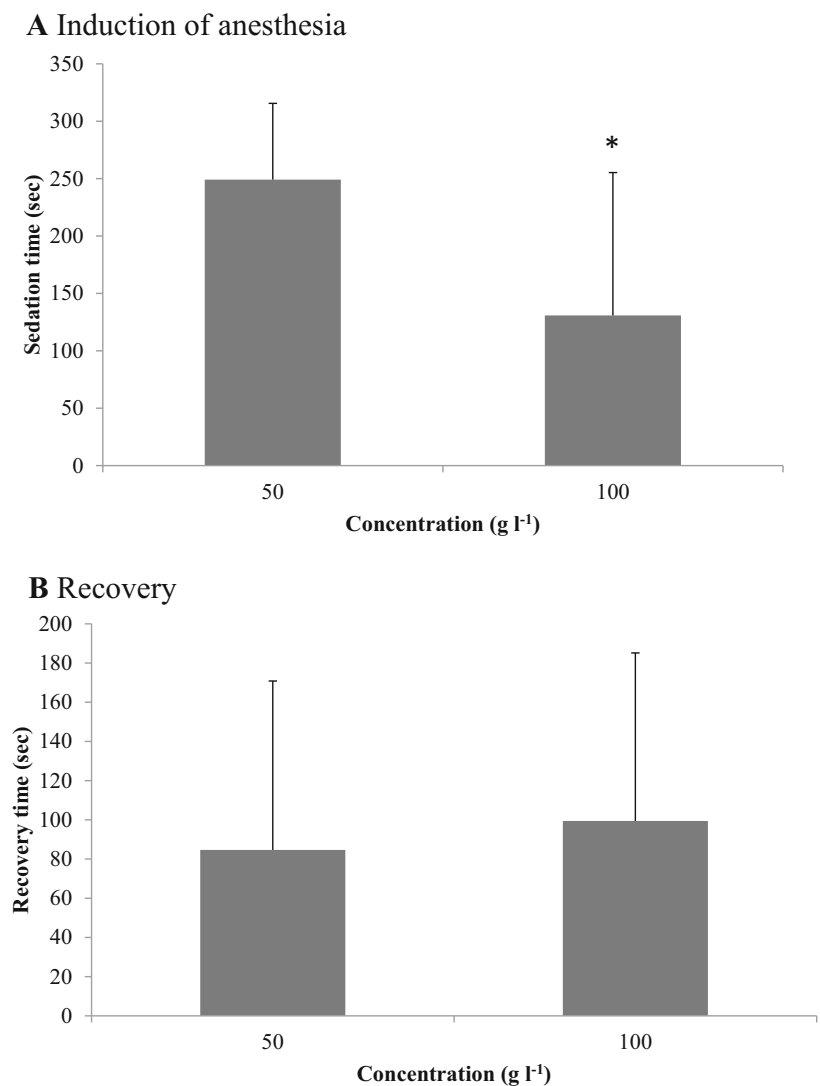

Fig. 2 Induction of anesthesia and recovery of red tilapia hybrid juveniles during immersion in brackishwater (20 ppt) containing 50 and $100 \mathrm{~g} \mathrm{l}^{-1}$ sodium bicarbonate. Column bars with asterisk indicates significant difference at $p<0.05 . N=9$

Table 2 Comparison between induction of anesthesia and recovery (in s) of red tilapia hybrid juveniles at two doses in fresh- and brackishwater

\begin{tabular}{lcr}
\hline & Induction of anesthesia & Recovery \\
\hline (a) $50 \mathrm{~g} \mathrm{l}^{-1}$ & & $110.9 \pm 92.7$ \\
Freshwater & $178.6 \pm 175.6^{*}$ & $84.7 \pm 86.2$ \\
Brackishwater & $249.1 \pm 66.4^{*}$ & \\
(b) $100 \mathrm{~g} \mathrm{l}^{-1}$ & & $78.3 \pm 73.5$ \\
Freshwater & $68.2 \pm 64.8$ & $99.4 \pm 85.7$ \\
Brackishwater & $130.9 \pm 124.4$ & \\
\hline
\end{tabular}

Values with asterisk in the same row indicate significant difference at $p<0.05 . N=9$. Each fish served as biological replicate for the experimental run

slower movements of the opercula. Upon induction of anesthesia (Stage III), the fish was not moving and was oriented on one side of its body. In addition, there was cessation of opercular movement. Upon transfer to the recovery aquarium, the fish slowly regained equilibrium and the opercula and the pectoral fins start to move slowly. Full recovery of the fish was attained when they exhibited the characteristics in the pre-anesthetic stage.

The water $\mathrm{pH}$ the freshwater aquaria was 7.6 before adding the sodium bicarbonate and increased to a $\mathrm{pH}$ level of 8.2 after adding 50 or $100 \mathrm{~g}^{-1}$ of the anesthetic. Similarly, in brackishwater the $\mathrm{pH}$ was 7.6 before the addition of the anesthetic, and increased to $\mathrm{pH} 8.0$ following the addition of either 50 or $100 \mathrm{~g}^{-1}$ of the anesthetic. 
Table 3 Comparison between fresh- and brackishwater on the induction of anesthesia and recovery (in s) of red tilapia hybrid juveniles at two doses of the anesthetic

\begin{tabular}{llc}
\hline & Freshwater & Brackishwater \\
\hline (a) $50 \mathrm{~g} \mathrm{l}^{-1}$ & & $249.1 \pm 66.4 *$ \\
$\quad$ Induction of anesthesia & $178.6 \pm 175.6$ & $84.7 \pm 86.2$ \\
Recovery & $110.9 \pm 92.7$ & \\
(b) $100 \mathrm{~g} \mathrm{l}^{-1}$ & & $130.9 \pm 124.4^{*}$ \\
Induction of anesthesia & $68.2 \pm 64.8$ & $99.4 \pm 85.7$ \\
Recovery & $78.3 \pm 73.5$ & \\
\hline
\end{tabular}

Values with asterisk in the same row indicate significant difference at $p<0.05 . N=9$. Each fish served as biological replicate for the experimental run

\section{Discussion}

The present study demonstrated that the use of sodium bicarbonate can be used as an effective anesthetic for red tilapia hybrid juveniles. In an earlier study, Opiyo et al. (2013) also showed that juveniles of Nile tilapia, $O$. niloticus responded positively to this substance when used as anesthetic and with no observed mortality. In other species of fish including rainbow trout, Oncorhynchus mykiss and common carp, Cyprinus carpio (Booke et al. 1978; Altun et al. 2009), sodium bicarbonate was used to anesthetize these species of fish and also showed potential to be used in the field during samplings. Complete knock-out of the fish was made possible when they were immersed in both fresh- and brackishwater that contained sodium bicarbonate enabled them to be easily manipulated (Burka et al. 1997), thus preventing any unwarranted stress during handling.

An acceptable anesthetic that can be used during fish handling is recommended to induce anesthesia in fish within 3 min and a complete recovery in 5 min (Marking and Meyer 1985; King et al. 2005; Ross and Ross 2008). In the present study, the use of sodium bicarbonate as anesthetic in red tilapia hybrid juveniles satisfied these requirements, except when this substance was used in brackishwater at a concentration of $50 \mathrm{~g} \mathrm{l}^{-1}$, where induction of anesthesia took more than $4 \mathrm{~min}$ on the average. In other species of fish, the use of sodium bicarbonate as anesthetic did not result in a satisfactory induction time to anesthesia. For example, walleye, Stizotedion vitreum were induced to anesthesia at $282 \mathrm{~s}$ when exposed to sodium bicarbonate at a concentration of $4 \mathrm{~g} \mathrm{l}^{-1}$. Common carp, C. carpio were fully anesthetized in 24-720 s when immersed in water containing $642 \mathrm{ppm}$ of sodium bicarbonate (Booke et al. 1978). The dose of the sodium bicarbonate that was used in the present study for complete induction of anesthesia in red tilapia juveniles was higher than the doses for other species of fish could be a result of the differences in the physiological responses of various species of fish to the anesthetic. It could not be discounted the fact that even within the same fish family such differences would also be manifested.

Brackishwater had good buffering capacity because of the presence of several ions that regulate the sudden changes in $\mathrm{pH}$ levels. The concentration of $50 \mathrm{~g} \mathrm{l}^{-1}$ sodium bicarbonate might not have caused a rapid release of carbon dioxide, which was responsible in anesthetizing the fish; hence, it took longer for the fish to exhibit the changes leading to anesthesia. Nevertheless, both concentrations of the sodium bicarbonate in freshwater resulted in the induction of anesthesia in the juvenile tilapias at a much faster rate. The results of our study were in agreement with an earlier study of Opiyo et al. (2013), where they showed that Nile tilapia juveniles in the size range of 2-4 g were induced to anesthesia within $3 \mathrm{~min}$ in freshwater at a concentration between 15 and $50 \mathrm{~g} \mathrm{l}^{-1}$. Sonawane and Kulkarni (2001) also demonstrated that the use of sodium carbonate at a concentration of $5 \mathrm{~g} \mathrm{l}^{-1}$ together with glacial acetic acid-induced anesthesia in gold spot mullet, Liza parsia fry in less than $3 \mathrm{~min}$. In addition, the higher the concentration of the anesthetic used resulted in shorter induction time for anesthesia, which was also obtained by Sonawane and Kulkarni (2001), Altun et al. (2009) and Opiyo et al. (2013). Previous studies demonstrated that induction time and recovery times of the fish can vary depending on the concentration of anaesthetic (Booke et al. 1978; Hseu et al. 1995; Yanar and Kumlu 2001), which was also observed in the present study.

Dissolving sodium bicarbonate in water liberates carbon dioxide gas. This gas is utilized for anaesthetic purposes in fish at various water temperatures and has been used primarily to sedate fish during transport or to 
allow handling large numbers of fish (Bowser 2001). It is suggested that the anesthetic response in fish was due to the $\mathrm{pH}$-controlled carbon dioxide release from sodium bicarbonate upon dissolving in water (Booke et al. 1978). Although carbon dioxide is useful for immobilization, its use as an anesthetic has many disadvantages, including difficulty in controlling concentrations in water, the need for maintaining high oxygen levels, and the occurrence of altered blood gases and acid-base balance in fish (Prince et al. 1995; Gelwicks et al. 1998; Harms 1999). We did not observe any mortality in red tilapia hybrid juveniles during anesthetization and post-recovery, indicating the slow release of carbon dioxide gas in the water after complete dissolution of sodium bicarbonate. In future studies, it is suggested that the actual concentration of the carbon dioxide that was liberated during the dissolution of sodium bicarbonate in water needs to be measured so that the anesthetic effect of this gas to the fish in relation to the amount of gas present is accurately determined.

The toxicological or long-term physiological effects of sodium bicarbonate in red tilapia hybrid juveniles was not evaluated, although monitoring the survival of the fish at 5 days post-recovery showed no mortality. However, future studies addressing these issues would be of considerable benefit particularly in elucidating the mechanisms of how fish responds to sodium bicarbonate long after it has been exposed to this anesthetic agent. The search for effective anesthetics that are suitable for use in handling and transport of fish without an excessive withdrawal time remains an immediate priority in aquaculture because fish end up in consumers as food. Commercial anesthetics, although some are generally regarded as safe (GRAS), are not recommended to be used in fish if these are immediately used for food. As novel chemicals that are safe for humans are being discovered for the immobilization of fish, the evaluation of their physiological effects and anesthetic efficacy must be carefully assessed. It is imperative that the efficacy and safety of these chemicals for use in fish are systematically, qualitatively, and quantitatively evaluated and at the same time their safety issues to the consuming public must be assessed as well.

Based on the results of this study, the effective dose of sodium carbonate that would lead to full anesthesia of red tilapia hybrid juveniles in either brackish- or freshwater is $50 \mathrm{~g}^{-1}$. At this concentration, the fish were anesthetized within a short period of time and could recover quickly without causing adverse effect on their survival post-exposure. A higher dose of sodium bicarbonate is needed in knocking out the fish because the fish were reared at higher water temperatures, which decreased the solubility of carbon dioxide in the water (Wedemeyer 1996).

\section{Conclusion}

In conclusion, the present study indicated that sodium bicarbonate can be an effective anesthetic for red tilapia hybrid juveniles during short-term handling and did not result in mortality of the fish during exposure to the anesthetic and during post-recovery. Regardless of the dose of the anesthetic, juvenile red tilapias that were reared in brackishwater took a longer time to be fully anesthetized than those reared in freshwater. In both rearing environments, the concentration of the anesthetic has an effect on the time to induce anesthesia of the fish. This study also highlighted that high concentration of sodium bicarbonate is needed to anaesthetize red tilapia hybrid juveniles at high water temperatures. The time to full recovery of the fish was not significantly different in both rearing environments and was not affected by the dose of the anesthetic. The application of sodium bicarbonate at a high $\mathrm{pH}$ level can be a good and inexpensive alternative to other anesthetics for fish.

Acknowledgements This study was funded by the CHED-NAFES Extension Project, "Western Philippines University Learning Environment-friendly Advocacy Farm and Family-based Education Towards Fisheries Resource Management and Popularization of Aquaculture and Alternative Agriculture in Western Philippines". CMA Caipang is supported by the Balik Scientist Program of the Department of Science and Technology, Philippines. The project staff of the CHED-NAFES project and some personnel of the College of Fisheries and Aquatic Sciences of WPU assisted in the conduct of this experiment.

\section{Compliance with ethical standards}

Conflict of interest On behalf of the co-author, I declare that there is no conflict of interest regarding the manuscript.

Open Access This article is distributed under the terms of the Creative Commons Attribution 4.0 International License (http:// creativecommons.org/licenses/by/4.0/), which permits unrestricted use, distribution, and reproduction in any medium, provided you give appropriate credit to the original author(s) and the source, provide a link to the Creative Commons license, and indicate if changes were made. 


\section{References}

Altun T, Bilgin R, Danabas D (2009) Effects of sodium bicarbonate on anaesthesia of common carp (Cyprinus carpio L., 1758) juveniles. Turkish J Fish Aquat Sci 9:29-31

Ashley PJ, Sneddon LU, McCrohan CR (2007) Nociception in fish: stimulus-response properties of receptors on the head of trout Oncorhynchus mykiss. Brain Res 1166:47-54

Bastos-Ramos WP, Goncalves NMFM, Bacila M (1998) Anesthesia and analgesia in Antarctic fish: an experimental approach. Arch Vet Sci 3:95-100

Bell GR (1987) An outline of anesthetics and anesthesia for salmonids, a guide for fish culturists in British Columbia. In Canadian technical report of fisheries and aquatic sciences no 1534, p 16

Bernier NJ, Randall DJ (1998) Carbon dioxide anaesthesia in rainbow trout: effects of hypercapnic level and stress on induction and recovery from anaesthetic treatment. J Fish Biol 52:621-637

Booke HE, Hollender B, Lutterbie G (1978) Sodium bicarbonate, an inexpensive fish anesthetic for field use. Progr Fish Cult 40:11-13

Bowser PR (2001) Anesthetic options for fish. In: Gleed RD and Ludders JW (eds) Recent advances in veterinary anaesthesia and analgesia: companion animals. International veterinary information service. Ithaca, New York. http://www.ivis.org/. Accessed 06 Mar 2019

Bruecker P, Graham M (1993) The effect of the anesthetic ketamine hydrochloride on oxygen consumption rates and behaviour in the fish Heros citrinellum (Gunther 1864). Comp Biochem Physiol 104C:57-59

Burka JF, Hammell KL, Horsberg TE, Johnson GR, Rainnie DJ, Speare DJ (1997) Drugs in salmonid aquaculture—a review. J Vet Pharmacol Ther 20:333-349

Fish FF (1943) The anesthesia of fish by high carbon dioxide concentrations. Trans Am Fish Soc 72:25-29

Gelwicks KR, Zafft DJ, Bobbitt JP (1998) Efficacy of carbonic acid as an anesthetic for rainbow trout. North Am J Fish Manag 18:432-438

Harms CA (1999) Anesthesia in fish. In: Fowler ME, Miller RE (eds) Zoo and wild animal medicine, current therapy 4. WB Saunders, Philadelphia, pp 158-163

Hseu JR, Yeh SL, Chu YT, Ting YY (1995) Application of sodium bicarbonate and sulfuric acid for anesthetization of black porgy Acanthopagrus schlegeli. J Taiwan Fish Res 3:151-159

Iwama GK, Ackerman P (1994) Anesthetics. In: Hochachka PW, Mommsen TP (eds) Biochemistry and molecular biology of fishes, vol 3. Elsevier Science, Amsterdam, pp 1-15

Iwama GK, McGeer JC, Pawluk MP (1989) The effects of five fish anesthetics on acid-base balance, hematocrit, blood gases, cortisol, and adrenaline in rainbow trout. Can J Zool 67:2065-2073

Keene JL, Noakes DLG, Moccia RD, Soto CG (1998) The efficacy of clove oil as an anaesthetic for rainbow trout, Oncorhynchus mykiss (Walbaum). Can Aquac Res 29:89-101

King WV, Hooper B, Hillsgrove S, Benton C, Berlinsky DL (2005) The use of clove oil, metomidate, tricaine methanesulphonate and 2-phenoxyethanol for inducing anaesthesia and their effect on the cortisol stress response in black sea bass (Centropristis striata L.). Aquac Res 36:1442-1449

Marking LL, Meyer FP (1985) Are better anesthetics needed in fisheries? Fisheries 10:2-5

Opiyo MA, Ochieng E, Charo-Karisa H (2013) Effectiveness of sodium bicarbonate as an anaesthetic for different sizes of Nila tilapia (Oreochromis niloticus L., 1758) juveniles. Int J Aquat Sci 4:14-22

Palić D, Herolt DM, Andreasen CB, Menzel BW, Roth JA (2006) Anaesthetic efficacy of tricaine methanesulfonate, metomidate and eugenol: effects on plasma cortisol concentration and neutrophil function in fathead minnows (Pimephales promelas Rafinesque. 1820). Aquaculture 254:675-685

Prince AMJ, Low SE, Lissimore TJ, Diewert RE, Hinch SG (1995) Sodium bicarbonate and acetic acid: an effective anesthetic for field use. North Am J Fish Manag 15:170-172

Ross LG, Ross B (2008) Anaesthetic and sedative techniques for aquatic animals. Blackwell Publishing, Oxford

Sneddon LU (2012) Clinical anesthesia and analgesia in fish. J Exotic Pet Med 21:32-43

Sneddon LU, Braithwaite VA, Gentle MJ (2003) Do fishes have nociceptors? Evidence for the evolution of a vertebrate sensory system. Proc R Soc Lond Ser B-Biol Sci 270:1115-1121

Sonawane UD, Kulkarni GN (2001) Anaesthetic effects of clove oil and sodium bicarbonate on the fry of Liza parsia. Iran J Fish Sci 3:49-62

Summerfelt RC, Smith LS (1990) Anaesthesia and surgery and related techniques. In: Schreck CB, Moyle PB (eds) Methods for fish biology. American Fisheries Society, Bethesda, pp 213-272

Wedemeyer GA (1996) Physiology of fish in intensive culture systems. Chapman and Hall, New York

Yanar M, Kumlu M (2001) The anaesthetic's effects of quinaldine sulphate and/or diazepam on sea bass (Dicentrarchus labrax) juveniles. Turk J Vet Anim Sci 25:185-189

Yoshikawa H, Kawai F, Kanamori M (1994) The relationship between the EEG and brain pH in carp, Cyprinus carpio, subjected to environmental hypercapnia at an anesthetic level. Comp Biochem Physiol 107A:307-312

\section{Publisher's Note}

Springer Nature remains neutral with regard to jurisdictional claims in published maps and institutional affiliations. 